\title{
DEVELOPMENT OF EMBRYOS RECOVERED FROM DOE RABBITS TREATED WITH GREEN TEA EXTRACT AND CULTURED UNDER HIGH THERMAL CONDITIONS IN VITRO
}

\author{
I.T. El-Ratel
}

Department of Poultry Production, Faculty of Agriculture, Damietta University, Damietta, Egypt

\section{SUMMARY}

This study aimed to evaluate whether orally treatment of doe rabbits with green tea extract (GTE) can eliminate the negative effects of hyperthermia on embryonic development in vitro. A total of 24 mature NZW does was randomly allotted into three groups, 8 in each. The $1^{\text {st }}$ group was control, while the $2^{\text {nd }}$ and $3^{\text {th }}$ groups were orally treated with $1 \mathrm{ml}$ distilled water contained 200 and $400 \mathrm{mg}$ GTE/kg LBW, respectively, for one month and naturally mated with proven bucks. Embryos were recovered from slaughtered doe oviducts at blastocyst stage $72 \mathrm{~h}$ post-mating by flushing and morphologically evaluated. Only normal embryos at blastocyst stage were in vitro cultured at $38.5{ }^{\circ} \mathrm{C}$ for $48 \mathrm{~h}$ (normal temperature, NT) or at $41.5^{\circ} \mathrm{C}$ (hyperthermia, HT) for $6 \mathrm{~h}$ then at $38.5{ }^{\circ} \mathrm{C}$ for $42 \mathrm{~h}$ in $5 \% \mathrm{CO}_{2}$ and $95 \%$ humidity to develop to expanded and hatched blastocysts. Results showed that embryo recovery rate was not significantly affected by GTE. Embryos of does treated with both GTE levels were better $(P<0.05)$ than control embryos. The GTE at $400 \mathrm{mg} / \mathrm{kg}$ showed the highest normality rates, hatched blastocyst proportion, and the lowest degenerated embryos. Formation rate of expanded and hatched blastocysts was higher $(P<0.05)$ for embryos cultured in vitro at NT than at HT, while proportion of degenerated embryos showed an opposite trend. Effect of interaction between GTE treatment and thermal condition was significant on proportion of expanded, hatched and degenerated embryos $(P<0.05)$, reflecting an increase in hatched embryos and decreasing degenerated embryos proportions by increasing GTE level at NT and HT, but GTE treatment showed the highest hatched and the lowest degenerated embryos proportions with level of $200 \mathrm{mg} / \mathrm{kg}$ at NT and with level of $400 \mathrm{mg} / \mathrm{kg}$ at HT. In conclusion, the negative effect of heat stress on embryonic development in vitro may be eliminated by GTE treatment of heat stressed does.

\section{Keywords: Rabbit, green tea, embryo, hyperthermia, in vitro co-culture}

\section{INTRODUCTION}

Reproductive efficiency of doe rabbits as mammals are very sensitive to confusion by high temperature in term of reduced yield and quality of embryos and subsequently affecting their fertility (Ondruska et al., 2011). Under intensive rabbit production system, several attempts have been carried out toward elimination of the negative effect of hot season on reproductive process (Askar and Ismail, 2012). In rabbits, embryos are more sensitive to thermal condition at earlier stage compared with embryos at 6-day old during in vitro development (Wolfenson and Blum, 1988) and short-term exposure of pre-implantation embryos to high temperature $\left(41.5^{\circ} \mathrm{C}\right)$ in vitro reduced development of embryos (Makarevich et al., 2007). Also, in mice, in vivo embryo development at an early stage to blastocysts was lower in warm than in cold season (Ozawa et al., 2004).

Evaluation of embryo developmental stage, basing on visual inspection of their morphology, is one of the useful criteria of pre-implantation embryo quality (kulíková et al., 2012). Pre-implantation embryos are sensitive to various stressors such as oxidative, chemicals, and hypothermic conditions. These stressors may cause developmental arrest in vitro (Olexikova et al., 2013). Also, these conditions may cause a reduction in embryo viability rate post- transfer (Al-Luhbi and Al-Bashan., 2013) as a result of cytoskeleton disorders, apoptosis (Makarevich et al., 2007), chromatin abnormality and acumulating the droplets of lipid (Qian et al., 2004 and Antonova, 2008). Under hyperthermia, reactive oxygen species (ROS) levels, as an oxidative stress, increase in association with damage of DNA (Alves et al., 2013). Glutathione (GSH) maintains the intracellular redox status of embryos and is associated with their development and quality in rabbits (Wells et al., 1997).

Hyperthermia is due to insufficient production of heat shock protein and GSH from the embryos (Alves et al., 2013), but most important role in the protection of pre-implantation embryo against high temperature is production of heat shock proteins 70 in response to thermal or other stressors (Hansen, 2007). These findings may indicate direct and indirect relationships between hyperthermia and oxidative stress during the development of embryos. Therefore, antioxidant administration to control the intra- or extra-cellular redox status (both in vivo and in vitro) may be a way to decrease heat stress related oxidative stress to improve quality and developmental competence of embryos (Abdel-Khalek et al., 2016 and Takahashi, 2012).

Recently, green tea is a very strong antioxidant and potent scavenger of free radicals and ROS in biological system. It also has properties for 
improving reproductive performance of rabbit does (El-Ratel et al., 2017). In mammals, influence of hyperthermic conditions on in vitro embryonic development depends on animal species, duration of embryo exposure, and embryonic stage (Makarevich et al., 2007). The protocols for in vivo and in vitro production of embryos resisted to heat stress are needed to better understanding the physiological responses of cells, gametes and embryos submitted to hyperthermic condition (Shehab El-Deen et al., 2010 and Payton et al., 2011).

Therefore, this study aimed to evaluate the resistance of pre-implantation embryos during in vitro development to hyperthermic condition $\left(41.5^{\circ} \mathrm{C}\right)$ as affected by treatment of doe rabbits with green tea extract (200 or $400 \mathrm{mg} / \mathrm{kg} \mathrm{LBW}$ ).

\section{MATERIALS AND METHODS}

\section{Animals:}

In this study, total of 24 New Zealand White (NZW) mature doe rabbits as embryo donors were randomly allotted into three groups ( 8 in each). The first was a control group without treatment, while the second and third groups were orally administrated with $1 \mathrm{ml}$ distilled water contained 200 and $400 \mathrm{mg}$ green tea extract (GTE, Arab Company for
Pharmaceuticals and Medicinal Plants, MepacoMedifood, Egypt) per $\mathrm{kg}$ live body weight, respectively, for one month prior to mating as a treatment period according to El-Ratel et al. (2017). Total of ten or twenty tablets (each tablet contained $300 \mathrm{mg}$ green tea as a dry extract, 30\% polyphenols) were dissolved in $15 \mathrm{ml}$ distilled water for obtaining oral dose of 200 or $400 \mathrm{mg} / \mathrm{ml}$ of GTE, respectively.

At the end of treatment period, does were naturally mated with proven bucks $(n=5)$ of the same breed. Then does were transported from farm $72 \mathrm{~h}$ post-mating to Physiology and Biotechnology Laboratory, Animal Production Department, Faculty of Agriculture, Mansoura University.

\section{Experimental procedures:}

Embryos were recovered from slaughtered does $72 \mathrm{~h}$ post-mating by flushing medium (phosphate buffer saline, PBS) containing 10\% fetal calf serum (FCS) and $50 \mu \mathrm{g}$ gentamycin $/ \mathrm{ml}$. Number of embryos at stage was recorded $(n=362)$ and morphologically evaluated for normal ( $\mathrm{n}=346$, Plate 1$)$ and abnormal $(\mathrm{n}=16$, Plate 2) embryos under stereoscopic microscope, morphology of mucin coat, zona pellucidae, blastomeres, and refractive cytoplasm after washing for 3 times in PBS.

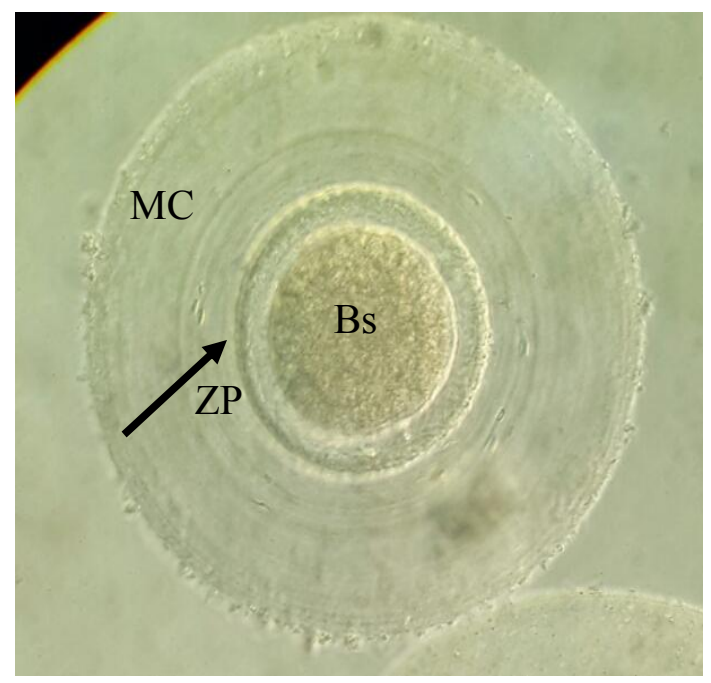

Plate 1. Normal embryo with intact mucin coat (MC), zona pellucidae (ZP)and blastomeres (Bs)

\section{Embryo culture in vitro:}

Only normal embryos at blastocyst stage $(n=346)$ were cultured in vitro under two thermal conditions (normal at $38.5{ }^{\circ} \mathrm{C}$ and hyperthermic at $41.5^{\circ} \mathrm{C}$ ) in $\mathrm{CO}_{2}$ incubator ( $95 \%$ humidity and $5 \% \mathrm{CO}_{2}$ in air) according to Olexiková et al. (2007). Embryos were cultured at normal temperature for $48 \mathrm{~h}(\mathrm{NT}, \mathrm{n}=174)$ or at hyperthermic condition $\left(41.5^{\circ} \mathrm{C}\right)$ for $6 \mathrm{~h}$ and at

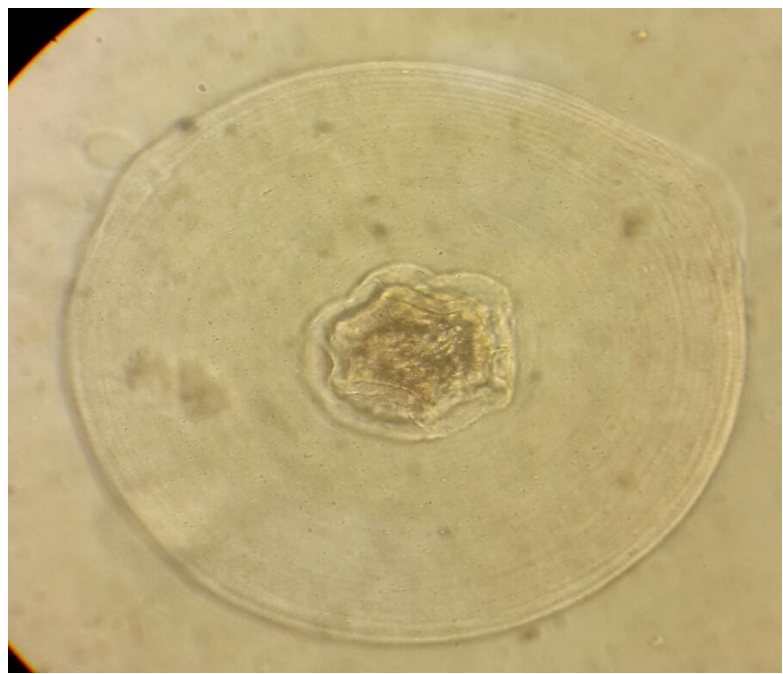

Plate 2. Abnormal embryo

normal temperature for $42 \mathrm{~h}(\mathrm{HT}, \mathrm{n}=172)$. All embryos were in vitro cultured in $500 \mu \mathrm{l}$ drops of tissue culture medium (TCM 199, Sigma) supplemented with $10 \%$ FCS and $50 \mu \mathrm{g}$ of Gentamicin sulphate/ml under mineral oil to develop into embryos at expanded (Plate 3) and hatched blastocyst (Plate 4) stages. 

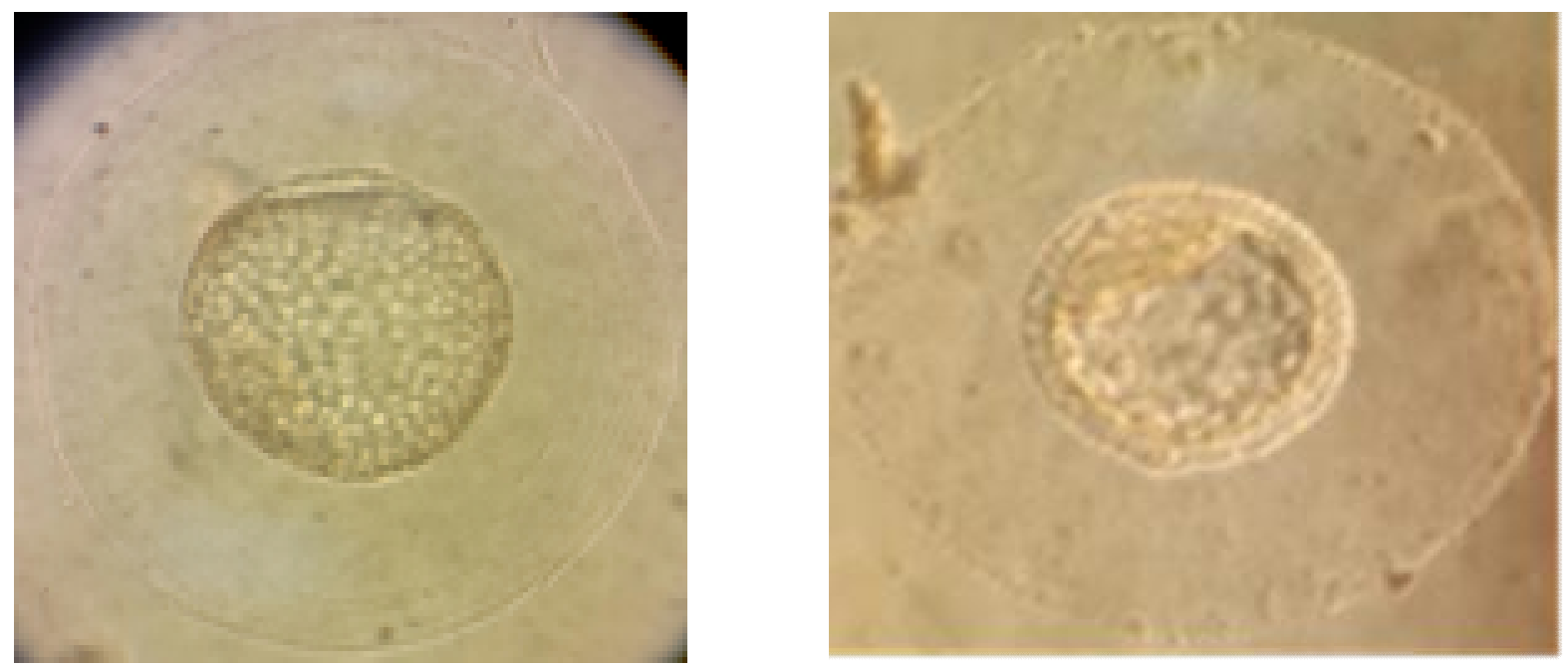

Plate 3. Embryos at expanded

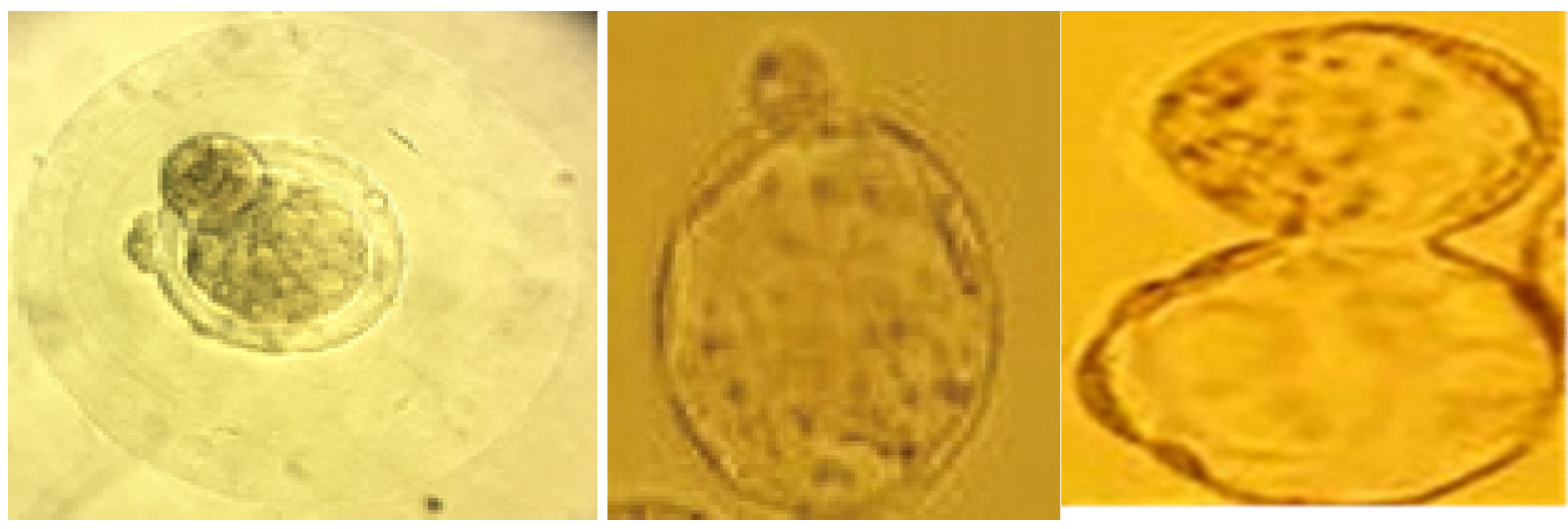

Plate 4. Embryos at hatched blastocyst stages

\section{Statistical analysis:}

The obtained data after arcsine transformation of original values expressed as precentages, including embryo recovery rate, normality and abnormality were statistically analyzed by one way design (NOVA), while the effect of GTE level and thermal condition on embryo development was performed using factorial design (3 GTE levels x 2 temperature condition) using a software package (SAS, 2004). The significant differences among means were tested using Duncan's Multiple Range Test (1955).

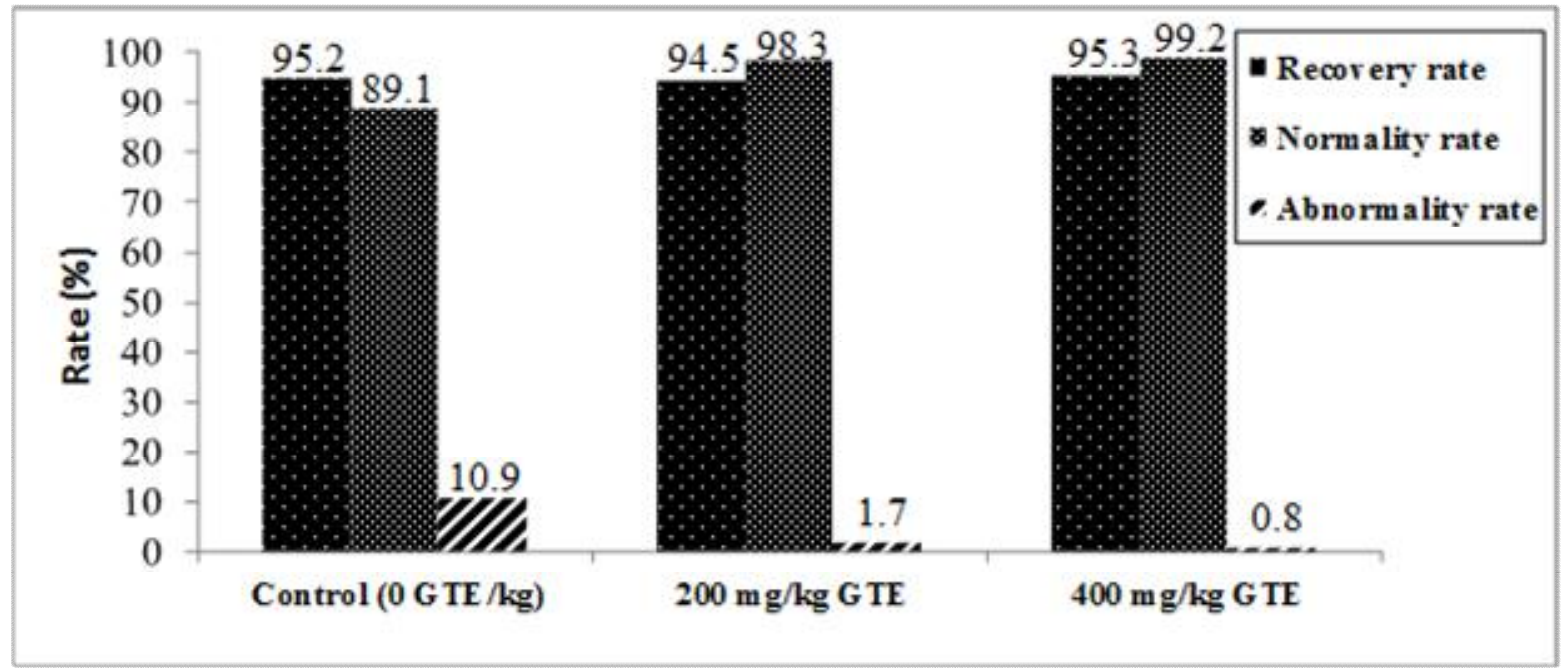

Fig 1. Rate of recovery, normality and abnormality of rabbit embryos as affected by green tea extract (GTE) orally treated doe rabbits. 



\section{RESULTS AND DISCUSSION}

\section{Recovery rate and embryo quality of doe rabbits treated with GTE:}

Although recovery rate of embryos was not significantly affected by GTE treatment, its quality significantly $(\mathrm{P}<0.05)$ differed, being better for embryos recovered from does treated with both levels of GTE than those recovered from control does. Generally, does treated with GTE at a level of 400 $\mathrm{mg} / \mathrm{kg}$ showed the highest normality rates (Fig. 1). These results indicated beneficial effect of GTE on quality of recovered embryos as compared to control.

Several authors indicated beneficial effects of in vivo antioxidant treatment of females on embryo quality. In rabbits, Abdel-Khalek et al. (2016) showed that daily oral administration of doe rabbits with Coenzyme Q10 or L-Carnitine as antioxidants can improve quality of recovered embryos. In human, dietary supplementation with Coenzyme Q10 may improve embryo quality (Bentov et al., 2010 and Scott, 2013). In mouse, in vivo administration of the antioxidant epigallocatechin gallate (EGCG) was found to improve embryo quality (Roth et al., 2008). In cattle, Amaral (2003) found that animals injected with vitamin $A$ on the $1^{\text {st }}$ day of the superovulation can increase number of viable embryos as compared to untreated animals.

In vivo embryonic development may be influenced by the ROS produced in the female genital system (Bedaiwy et al., 2002). According to Du Plessis et al. (2008), in vivo embryos rely on mitochondrial oxidative phosphorylation for energy, a process which is subsequently accompanied by ROS generation (Du Plessis et al., 2008). The antioxidant capacity of the embryos against the harmful assault of oxidation, because the fast developing embryo produces energy via ATP generation through mitochondrial oxidative phosphorylation and glycolysis (Agarwal et al., 2014). As it develops, the embryo is capable of producing ROS through several pathways, namely oxidative phosphorylation, NADPH and xanthine oxidase systems (Guerin et al., 2001).

This finding concurs with the results observed in the current study may be justified the establishment of supplementation antioxidants (GTE) promoted equilibrium between oxidative agents and the antioxidative system, which may have improved embryo quality.

Developmental competence of embryos recovered from does treated with GTE and cultured at normal and hyperthermic condition:

\section{Effect of GTE treatment:}

Regardless co-culture temperature, treatment of does with GTE at a level of $400 \mathrm{mg} / \mathrm{kg}$ LBW yielded significantly $(\mathrm{P}<0.05)$ the highest frequency distribution of hatched blastocysts, and the lowest distribution of degenerated embryos, while distribution of expanded blastocysts was not affected significantly by GTE treatment (Table 1).

Table 1. Developmental competence of embryos recovered from doe rabbits treated with green tea extract (GTE)

\begin{tabular}{|c|c|c|c|c|c|c|c|}
\hline & \multirow{3}{*}{$\begin{array}{c}\text { Total } \\
\text { number of } \\
\text { embryos }\end{array}$} & \multicolumn{4}{|c|}{ Developmental stage } & \multirow{2}{*}{\multicolumn{2}{|c|}{$\begin{array}{c}\text { Degenerated } \\
\text { embryos }\end{array}$}} \\
\hline & & \multicolumn{2}{|c|}{ Expanded blastocyst } & \multicolumn{2}{|c|}{ Hatched blastocyst } & & \\
\hline & & $\mathbf{N}$ & $\%$ & $\mathbf{n}$ & $\%$ & $\mathbf{n}$ & $\%$ \\
\hline Control & 106 & 52 & 49.06 & 30.00 & $28.30^{\mathrm{b}}$ & 24 & $22.64^{\mathrm{a}}$ \\
\hline GTE $(200 \mathrm{mg} / \mathrm{kg})$ & 118 & 56 & 47.46 & 42 & $35.59^{\mathrm{ab}}$ & 20 & $16.95^{\mathrm{b}}$ \\
\hline GTE $(400 \mathrm{mg} / \mathrm{kg})$ & 122 & 62 & 50.82 & 44 & $36.07^{\mathrm{a}}$ & 16 & $13.11^{\mathrm{b}}$ \\
\hline \pm SEM & & \multicolumn{2}{|c|}{1.77} & \multicolumn{2}{|c|}{2.51} & \multicolumn{2}{|c|}{1.79} \\
\hline Significance & & \multicolumn{2}{|c|}{ NS } & \multicolumn{2}{|c|}{$*$} & \multicolumn{2}{|c|}{$* *$} \\
\hline
\end{tabular}

and $\mathrm{b}$ : Means with different letters in the same column differ significantly at $\mathrm{P}<0.05$.

NS = not significant. * Significant at $\mathbf{P}<0.05$. ** Significant at $\mathbf{P}<0.01$.

In accordance with the present results, Roth et al. (2008) reported that in vivo administration of EGCG in GT as antioxidant improved developmental competence of mouse embryos. Also, Cerri et al. (2009) found that increased selenium of the reproductive tract in dairy cows may improve competence of embryo development, pregnancy and fetal development. This was indicated in the current study in doe rabbits treated with GTE. Furthermore, impact of different types of antioxidant in in vitro culture medium, on developmental competence of embryos was proved by several workers. In this line, addition of melatonin at a level of $10^{-6} \mathrm{M}$ for rabbit embryos (Mehaisen and Saeed, 2015), GT polyphenols for bovine embryos (Wang et al., 2013), and L-Carnitine (Abdelrazik et al., 2009) and vitamin C at a level of
$50 \mu \mathrm{mol} / \mathrm{L}$ for mouse embryos (Wang et al., 2002) markedly improved embryo development rate in vitro.

Improving the developmental competence of embryos produced from doe rabbits treated with GTE may be attributed to that exogenous antioxidants activities of phenolic compounds in GT are due to their structure and particularly ability to donate a hydrogen ion to the peroxy radical generated as a result of lipid peroxidation (Bisby et al. 2008). Also, Agarwal et al. (2003) mentioned that in vitro blastocyst formation is suboptimal, and supplementation with antioxidants may improve blastocyst development. According to the present results and the previous findings, antioxidants such as GTE, are likely to play a significant role in 
preventing subsequent loss or damage to the embryo (Abdelrazik et al., 2009). Finally, Barakat et al. (2014) showed that GTE acts as a direct scavenger of toxic oxygen derivatives and has the ability to reduce the formation of ROS and promotes DNA synthesis of embryos and intracellular.

\section{Effect of co-culture temperature:}

Regardless GTE treatment, the formation rate of expanded and hatched blastocysts was significantly $(\mathrm{P}<0.05)$ higher for embryos cultured in vitro in normal temperature $\left(38.5^{\circ} \mathrm{C}\right)$ than at hyperthermic condition $\left(41.5^{\circ} \mathrm{C}\right)$. However, frequency distribution of degenerated embryos showed an opposite trend (Table 2).

These results indicated hyperthermia conditions $\left(41.5^{\circ} \mathrm{C}\right)$ during co-culture did not stop progress of embryos to hatched blastocyst stage, but significantly decreased the developmental competence of embryos by about $31.07 \%$ and increased embryo degeneration by about 203.4\%. Although, Ealy et al. (1995) reported that the development of 2-16 cell stage or more cell stage of bovine embryos was damaged and not cleavage following heat shock at $41^{\circ} \mathrm{C}$ for $3 \mathrm{~h}$, exposing the rabbit embryos in the present study to hyperthermia conditions at $41.5{ }^{\circ} \mathrm{C}$ allowed the embryos to develop up to hatched blastocysts, but at lower proportion than at normal temperature. However, increasing hyperthermia condition to 42.5 ${ }^{\circ} \mathrm{C}$ decreased development of rabbit embryos to preimplantation stages, and all embryos were arrested only at early blastocyst stage (Olexiková et al ., 2007). Also, hyperthermia reduced the proportion of mouse pre-implantation embryos at different stages and changed the developmental capacity (Zhu et al., 2004). In accordance with the obtained results in rabbits, it was found that hyperthermia conditions at $41.5{ }^{\circ} \mathrm{C}$ (Silva et al., 2013) or $41{ }^{\circ} \mathrm{C}$ (Sakatani et al., 2004) decreased developmental rates of bovine embryos.

In similar trend with the observed increase in proportion of degenerated embryos as affected by hyperthermia, several authors showed that the chronic elevation of temperature above the normal culture temperature $\left(38.5-40{ }^{\circ} \mathrm{C}\right)$ in vitro resulted in a higher incidence of embryo death that was evident shortly after embryo hatching (Makarevich et al., 2007; Ryan et al., 1992).

Table 2. Developmental competence of rabbit embryos as affected by in vitro co-culture temperature

\begin{tabular}{|c|c|c|c|c|c|c|c|}
\hline \multirow{3}{*}{ Temperature } & \multirow{3}{*}{$\begin{array}{c}\text { Total } \\
\text { number of } \\
\text { embryos }\end{array}$} & \multicolumn{4}{|c|}{ Developmental stage } & \multirow{2}{*}{\multicolumn{2}{|c|}{$\begin{array}{c}\text { Degenerated } \\
\text { embryos }\end{array}$}} \\
\hline & & \multicolumn{2}{|c|}{ Expanded blastocyst } & \multicolumn{2}{|c|}{ Hatching blastocyst } & & \\
\hline & & $\mathbf{N}$ & $\%$ & $\mathbf{n}$ & $\%$ & $\mathbf{n}$ & $\%$ \\
\hline Normal & 174 & 90.00 & $51.72^{\mathrm{a}}$ & 69.00 & $39.65^{\mathrm{a}}$ & 15.00 & $8.62^{b}$ \\
\hline Hyperthermia & 172 & 80.00 & $46.51^{\mathrm{b}}$ & 47.00 & $27.33^{\mathrm{b}}$ & 45.00 & $26.16^{\mathrm{a}}$ \\
\hline \pm SEM & & \multicolumn{2}{|c|}{1.44} & \multicolumn{2}{|c|}{2.05} & \multicolumn{2}{|c|}{1.47} \\
\hline Significance & & \multicolumn{2}{|c|}{$* *$} & \multicolumn{2}{|c|}{$* *$} & \multicolumn{2}{|c|}{$* * *$} \\
\hline
\end{tabular}

and $b$ : Means with different letters in the same column differ significantly at $P<0.05$.

** Significant at $\mathbf{P}<0.01$. *** Significant at $\mathbf{P}<0.001$.

\section{Effect of interaction:}

Effect of interaction between GTE treatment and thermal condition was significant $(\mathrm{P}<0.05)$ on proportion of expanded, hatched and degenerated embryos. These effects reflected in increasing proportion of hatched embryos and decreasing degenerated embryos by increasing GTE level at both normal and hyperthermia conditions, but GTE treatment showed the highest hatched and the lowest degenerated embryos proportion with level of 200 $\mathrm{mg} / \mathrm{kg}$ at normal condition and with level of 400 $\mathrm{mg} / \mathrm{kg}$ at hyperthermia condition. In addition, proportion of expanded embryos decreased at the normal condition and increased at hyperthermia condition by increasing GTE level (Fig. 2).

Such results indicated more beneficial effects of GTE at a level of $200 \mathrm{mg} / \mathrm{kg}$ at the normal condition and the significant impact of increasing this level at hyperthermia condition up to $400 \mathrm{mg} / \mathrm{kg}$.

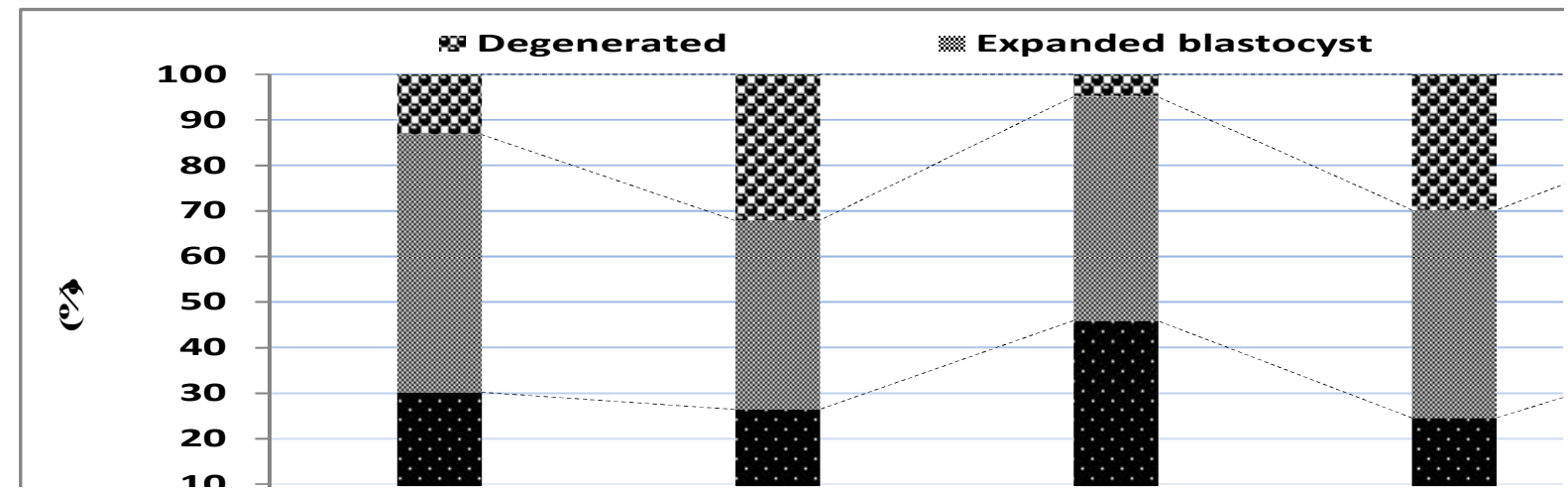

Fig 2. Frequency distribution of embryos at hatched, expanded and degenerated stages cultured at normal (NT) and hyperthermic condition (HT) and recovered from doe rabbits treated with green tea extract (GTE). 
Thermo-tolerance of embryos is generally affected by many factors, such as heat shock duration, temperature degree, embryonic developmental stage and animal species (Makarevich et al., 2007). In bovine, embryo developmental capacity was decreased under hyperthermia condition of $43{ }^{\circ} \mathrm{C}$ (Ju et al., 1999), and the development to

The sensitivity of pre-implantation embryos to different stress conditions (oxidation, toxicity and hypothermia) causes various types of embryo damage, in terms of mitochondrial and lysosomal changes as well as accumulation of lipid droplets (Olexikova et al., 2013). During heat shock, free radical production had been suspected leading to promote oxidation events in the cell (Ara Ahmed et al., 2016). In vivo or in vitro heat stress caused a decrease in GSH of embryos, and elevated ROS levels associated with DNA damage in mice (Ozawa et al., 2002).

Addition of exogenous antioxidants during the development of bovine embryos is important to provide hyper-thermo resistance to overcome the negative effects (Rynkowska, 2011), which increase the chance of embryos, even those of fair quality, to develop to blastocysts. Supplementations of antioxidants at optimal levels have been demonstrated to have a positive effect on embryo development (Ara Ahmed et al., 2016). In this respect, melatonin administration to heat-stressed mice alleviated hyperthermia-induced early embryonic death (Matsuzuka et al., 2005). Also, vitamin $\mathrm{E}$ protects the early embryo from the effects of ambient heat stress (Arechiga et al., 1995). In rats (Ishibashi et al., 1997) and rabbits (Wells et al., 1997), GSH maintains the intracellular redox status of embryos and was associated with their development and quality. The GSH can improve the thermo-tolerance of embryos (Arechiga et al., 1995). Generally, under heat stress condition, in vitro antioxidant administration improved bovine embryo development, which was associated with intracellular ROS and GSH synthesis (Sakatani et al., 2008).

During embryonic development, the current study indicated direct and indirect relationships between in vitro hyperthermia condition and oxidative stress. Using GTE as antioxidant to control the intracellular or extracellular redox status both in vivo and in vitro may be a way to reduce heat stress-related oxidative stress. Therefore, the deleterious effects of heat stress, either in vivo or in vitro, in terms of reduction in embryo viability (Al-Luhbi and Al-Bashan., 2013) and pregnancy rate, and increasing embryonic losses (Block and Hasen., 2007) was previously reported.

\section{CONCLUSION}

The negative effect of heat stress on embryonic development in vitro may be eliminated by GTE orally treated doe rabbits, in particular at a level of $400 \mathrm{mg} / \mathrm{kg}$. However, treatment of doe rabbits with blastocyst and proliferation reduced under heat stress at an early stage (Sakatani et al. (2004). Under hyperthermia condition $\left(43-45.5^{\circ} \mathrm{C}\right)$, disturbance in the development of pig embryos was proved after short-term exposure (10-60 $\mathrm{min})$, while at $42{ }^{\circ} \mathrm{C}$ the embryos had even a higher cell number and diameter than at control temperature (Kojima et al. 1996).

GTE at a level of $200 \mathrm{mg} / \mathrm{kg}$ is sufficient at the normal thermal condition.

\section{REFERENCES}

Abdel-Khalek, A.E., I.T. El-Ratel, W.M. Wafa, H.A. El-Nagar, G.E. Younan and Sara F. Fouda, 2016. Effect of pre-conception coenzyme Q10 and Lcarnitine treatments on ovulatory response, genital characteristics and in vitro embryo characteristics in rabbits. Asian J. Anim. Vet. Adv., (11): 53-59.

Abdelrazik, H., Sh. Rakesh, M. Reda and A. Ashok, 2009. L-Carnitine decreases DNA damage and improves the in vitro blastocyst development rate in mouse embryos. Fertil Steril (2): 589- 596.

Agarwal, A., D. Durairajanayagam and S. S. du Plessis, 2014. Utility of antioxidants during assisted reproductive techniques: An evidence based review. Reprod. Biol. Endocrinol., (12): 112-130.

Agarwal, A., R.A. Saleh and M.A. Bedaiwy, 2003. Role of reactive oxygen species in the pathophysiology of human reproduction. Fertil Steril. (79): 829-843.

Al-Luhbi, F .M and M. M. Al-Bashan, 2013. Toward a rabbit-optimized culture medium: impact of supplementation with amino acids on early development of in vitro cultured rabbit embryos. World J. Zool., (4): 344-353.

Alves, M. F., F. G. Roseli, L. P. Danielle, G. P. Eduardo, S. Flavio, K. Roberta, D. Magali and A. Marcos, 2013. Effect of heat stress on the maturation, fertilization and development rates of in vitro produced bovine embryos. Open Journal of Animal Sciences, (3): 174-178.

Amaral, B.C. 2003. Utilizac, ao de vitamina A injet'avel em diferentes concentrac, oes na produc, ao e qualidade de embrĩoes bovinos, Dissertation (Master in Animal Science) - Universidade Federal de Lavras, Lavras, 48 pp.

Antonova, E. I. 2008. Ultrastructural manifestations of the primary compensatory-adaptive response of hepatocytes in animals with various thermos regulation after exposure to hyperthermia. Morfologiia, (133): 24-28.

Askar, A.A. and El. I. Ismail, 2012. Impact of heat stress exposure on some reproductive and physiological traits of rabbit does. Egyptian J. Anim. Prod. (49):151-159.

Ara Ahmed, J., D. Dutta and N. Nashiruddullah, 2016. Comparative efficacy of antioxidant retinol, melatonin, and zinc during in vitro maturation of bovine oocytes under induced heat stress. Turk J Vet Anim Sci (40): 365-373.

Arechiga, C.F., A.D. Ealy and P.J. Hansen, 1995. Evidence that glutathione is involved in 
thermotolerance of preimplantation murine embryos. Biol Reprod. (52): 1296-1301.

Barakat, I. A. H., R. A. Ahmad and M. R. Ahmed, 2014. Antioxidant effect of green tea leaves extract on in vitro production of sheep embryos. Pakistan J. Zool., (46): 167-175.

Bedaiwy, M.A., J.M. Goldberg, T. Falcone, M. Singh, D. Nelson and H. Azab, 2002. Relationship between oxidative stress and embryotoxicity of hydrosalpingeal fluid. Hum. Reprod. (17): 601-604.

Bentov, Y., N. Esfandiari, E. Burstein and R.F. Casper, 2010. The use of mitochondrial nutrients to improve the outcome of infertility treatment in older patients. Fertil. Steril.,(93): 272-275.

Bisby, R. H., R. Brooke and S. Navaratnam, 2008. Effect of antioxidant oxidation potential in the oxygen radical absorption capacity (ORAC) assay. Food Chemistry, (108): 1002-1007.

Block, J. and P.J. Hasen, 2007. Interaction between season and culture with insulin-like growth factor-1 on survival of in vitro produced embryos following transfer to lactating dairy cows. Theriogenology (67): 1518-1529.

Cerri, R. L., H. M. Rutigliano, F. S. Lima, D. B. Araújo and J. E. Santos, 2009. Effect of source of supplemental selenium on uterine health and embryo quality in high-producing dairy cows. Theriogenology, (71): 1127-1137.

Duncan, D.B. (1955). Multiple range and Multiple F test. Biometrics, 11:1-42.

Du Plessis, S.S., K. Makker, N.R. Desai and A. Agarwal, 2008. Impact of oxidative stress on IVF. Expet Rev. Obstet. Gynecol., (3): 539-554.

Ealy, A. D., L. J. L. Howel, V. H. Monterosso, C. F. Arechiga and P. J. Hansen, 1995. Developmental changes in sensivity of bovine embryos to heat shock and use of antioxidants as thermoprotectants. In: Journal of Animal Scienace. (73):1401-1407.

El-Ratel, I.T., A.E., Abdel-Khalek, M.A. El-Harairy, Sara F. Fouda and Lamiaa Y. El-Bnawy, 2017. Impact of green tea extract on reproductive performance, hematology, lipid metabolism and histogenesis of liver and kidney of rabbit does. Asian J. Anim. Vet. Adv., (12): 51-60.

Guerin, P., S. El Mouatassim and Y. Menezo, 2001. Oxidative stress and protection against reactive oxygen species in the pre-implantation embryo and its surroundings. Hum. Reprod Update, (7): 175189.

Hansen, P. J. 2007. Determinants of embryonic survival following heat shock. In: Theriogenology, (68): 4048.

Ishibashi, M., S. Akazawa, H. Sakamaki, K. Matsumoto, H. Yamasaki, Y. Yamaguchi, S. Goto, Y. Urata, T. Kondo, and S. Nagataki, 1997. Oxygeninduced embryo pathy and the significance of glutathione- dependent antioxidant system in the rat embryo during early organogenesis. Free Radic Biol Med. (22): 447-454.

Ju, J.C., J.E. Parks, and X. Yang, 1999. Thermotolerance of IVM-derived bovine oocytes and embryos after short-term heat shock. Mol Reprod Dev., (53); 336-340.

Kojima, T., K. Udagawa, A. Onishi, H. Iwahashi and Y. Komatsu, 1996. Effect of heat stress on development in vitro and in vivo and on synthesis of heat shock proteins in porcine embryos. Mol Reprod Dev., (43): 452-457.

Kulíková, B., J.R. Slamečka, A.V. Makarevich and P. Chrenek, 2012. Effect of in vitro culture conditions on the quality of rabbit embryos. Slovak J. Anim. Sci., (4): 123-126.

Makarevich, A.V., L. Olexiková, P. Chrenek, E. Kubovičová, K. Fréharová and J. Pivko, 2007. The Effect of Hyperthermia in vitro on Vitality of Rabbit Preimplantation Embryos. Physiol. Res., (56): 789796.

Matsuzuka, T., M. Ozawa, M. Hirabayashi, A. Ushitani and Y. Kanai, 2004. Developmental competence and glutathione content of maternally heat-stressed mouse oocytes and zygotes. Anim. Sci. J. (75):117-124.

Mehaisen, G. M. K. and A. M. Saeed, 2015. In vitro development rate of preimplantation rabbit embryos cultured with different levels of melatonin. Zygote, (23): 111-115.

Olexikova, L., A. V. Makarevich, J. Pivko and P. Chrenek, 2013. Ultrastructure of Rabbit Embryos Exposed to Hyperthermia and Anti-Hsp 70. Anat. Histol. Embryol. (42): 285-291.

Olexiková, L., A.V. Makarevič, P. Chrenek, E. Kubovičová, and J. Pivko, 2007. Development of rabbit preimplantation embryos under thermal stress in vitro .Slovak J. Anim. Sci., (2): 63 - 65.

Ondruska, L., J. Rafay, A.B. Okab, M.A. Ayoub, A.A. Al-Haidary, E.M. Samara, V. Parkanyi, L. Chrastinova, R. Jurcik, P. Massanyi, N. Lukac and P. Supuka, 2011. Influence of elevated ambient temperature upon some physiological measurements of New Zealand White rabbits. Original Paper Veterinarni Medicina, (4): 180-186.

Ozawa, M., T. Matsuzuka, M. Hirabayashi and Y. Kanai, 2004. Redox status of the oviduct and CDC2 activity in 2-cell stage embryos in heat-stressed mice. Biol Reprod. (71): 291-296.

Ozawa, M., M. Hirabayashi and Y. Kanai, 2002. Developmental competence and oxidative state of mouse zygotes heat-stressed maternally or in vitro. Reproduction. (124):683-9.

Payton, R.R., L.A. Rispoli, A.M. Saxton and J.L. Edwards, 2011. Impact of heat stress exposure during meiotic maturation on oocyte, surrounding cumulus cell, and embryo RNA populations. Journal of Reproduction and Development, (4): 481-491.

Qian, L., X. Song, H. Ren, J. Gong and S. Cheng, (2004). Mitochondrial mechanism of heat stressinduced injury in rat cardiomyocyte. Cell Stress Chaperones. (9): 281-293.

Ryan, D.P., E.G. Blakewood, J.W. Lynn and L. Munyakazi, 1992. Effect of heat-stress in bovine embryo development in vitro. J Anim Sci (70): 34903497. 
Rynkowska, A., Ł. Rąpała, P. Trzeciak and A.M. Duszewska, 2011. The application of in vitro cattle embryo production system to study the influence of elevated temperature on oocyte maturation, fertilization and early embryonic development. BioTechnologia, (1): 45-53.

Roth, Z., A. Aroyo, S. Yavin and A. Arav, 2008. The antioxidant epigallocatechin gallate (EGCG) moderates the deleterious effects of maternal hyperthermia on follicle-enclosed oocytes in mice. Theriogenology (70): 887-897.

Sakatani, M., K. Yamanaka, S. Kobayashi and M. Takahashi, 2008. Heat shock derived reactive oxygen species induce embryonic mortality in in vitro early stage bovine embryos. J Reprod Dev. (54): 496-501.

Sakatani, M., S. Kobayashi and M. Takahashi, 2004. Effects of heat shock on in vitro development and intracellular oxidative state of bovine preimplantation embryos. Mol Reprod Dev (67): 7782.

SAS, 2004. SAS Institute Inc. SAS User's Guide, Statistics. Cary, NC.

Scott, Ch. 2013.The role of mitochondria from mature oocyte to viable blastocyst. Obstetrics and Gynecology International, 1-10.

Shehab El-Deen, M.A.M.M., J.L.M.R. Leroy, M.S. Fadel, S.Y.A. Saleh, D. Maes and A. Van Soom, 2010. Biochemical changes in the follicular fluid of the dominant follicle of high producing dairy cows exposed to heat stress early post-partum. Animal Reproduction Science, (117): 189-200.
Silva, C.F., E.S. Sartorelli, A.C.S. Castilho, R.A. Satrapa, R.Z. Puelker, E.M. Razza, J.S. Ticianelli, H.P. Eduardo, B. Loureiro and C.M. Barros, 2013. Effects of heat stress on development, quality and survival of Bos indicus and Bos taurus embryos produced in vitro. Theriogenology (79): 351-357.

Takahashi, M. (2012). Heat stress on reproductive function and fertility in mammals. Reprod Med Biol (11): 37-47.

Wang, Z., Ch. Fu and S.Yu, 2013. Green tea polyphenols added to IVM and IVC media affect transcript abundance, apoptosis, and pregnancy rates in bovine embryos. Theriogenology (79): 186-192.

Wang, X., T. Falcone, M. Attaran, J. M. Goldberg, A. Agarwal and R. K. Sharma, 2002. Vitamin C and vitamin $\mathrm{E}$ supplementation reduce oxidative stressinduced embryo toxicity and improve the blastocyst development rate. Fertility and Sterility, (78): 12711277.

Wells, P.G., P.M. Kim, R.R. Laposa, C.J. Nicol, T. Parman and L.M. Winn, 1997. Oxidative damage in chemical teratogenesis. Mutat Res. (396): 65-78.

Wolfenson, D. and O. Blum, 1988. Embryonic development, conception rate, ovarian function and structure in pregnant rabbits heat-stressed before or during implantation. Anim Reprod Sci (17): 259270.

Zhu, B., S. K. Walker, H. Oakey, B. P. Setchell and S. Maddocks, 2004. Effect of paternal heat stress on the development in vitro of preimplantation embryos in the mouse. Andrologia (36): 384-394.

\title{
تظور الأجنة المستردة من أمهات الأرانب المعاملة بمستخلص الثاى الأخضر والمنزرعة تحت درجات حرارة مرتفعة معملياً
}

\author{
إبر اهيم طلعت الرطل \\ قسم إنتاج الدواجن، كلية الزراعة، جامعة دمياط، دمياط، مصر
}

تهدف هذه الدر اسة الى تقيم ما اذا كانت المعاملة بتجريع امهات الار انب بمستخلص الثاى الاخضر يمكن ان يحد من التأثير السلبى للحر ارة العالية

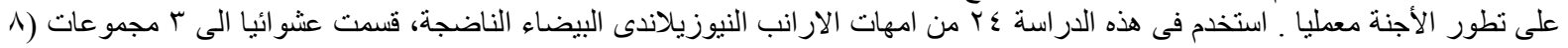

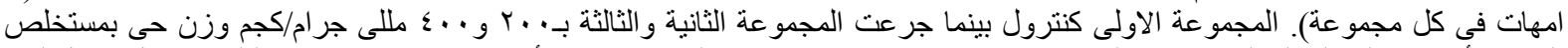

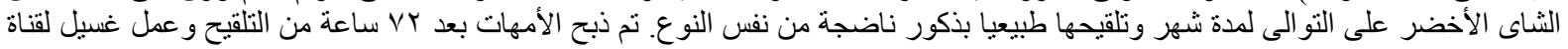

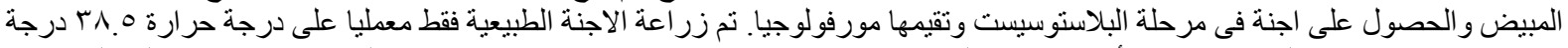

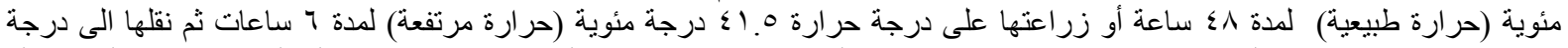

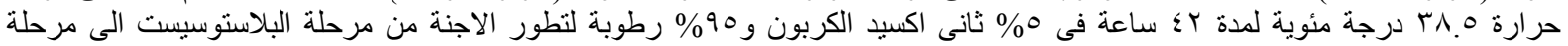

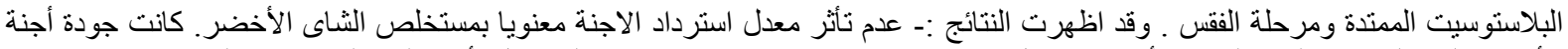

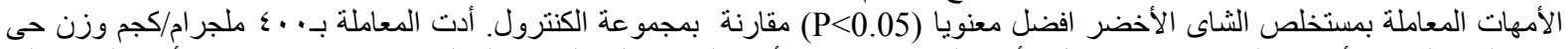

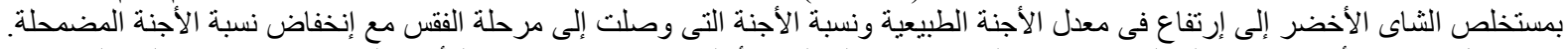

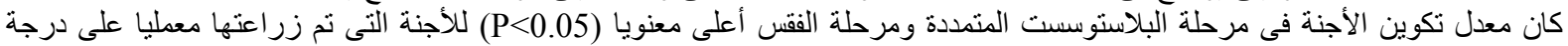

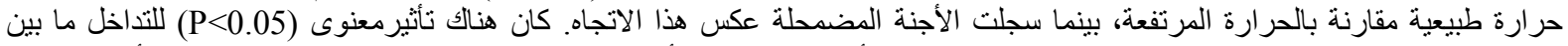

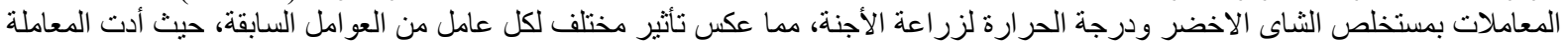

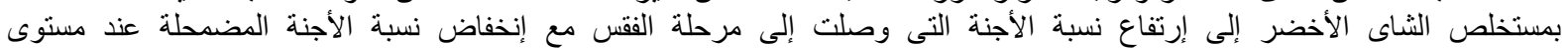

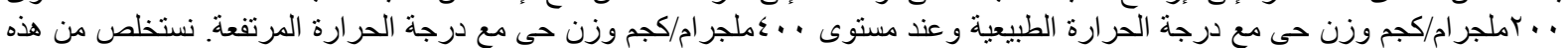

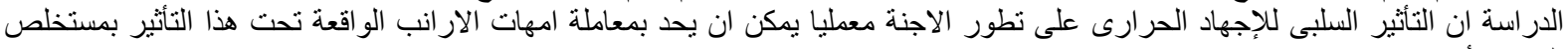

